\title{
The Mouth Will Taste Its Own Fears
}

In the kitchen the curtains imitate wind. The blue lights of the police

car twist out of the dark outside.

They're coming for you, Isabel.

They heard about the glow of your skin, the picture of the hands holding

mandarins, how you denied

for years that the hands were yours,

that the mandarins were real, that any

of it ever happened. It happened,

Isabel. There's a man

with a hole in his heart to prove it.

\section{Dream-of-the-Month Club}

You have a hunger for the Latin boys, always standing at the edge of a trend. You softshoe your way into the heart of anyone with a pair of dark eyes and a good radio. There goes the neighborhood, you said, watching the blonds move in with their red cars, their subtle lines, the keys to their old houses still in their pockets. Another migration of pale boys with new wives like birds out of season. All desire has a price and everything costs more at this end of town. Even the building on 27th Avenue (the one that came out of nowhere, remember?) is beginning to look dated, not quite as tall as it seemed in the beginning, not quite as important in the midst of things. The Latin boys are listening to country music in their cars, a sign of something - age, the times, fear of being noticed. Remember, when you were a child you'd shut your eyes to disappear. It worked then, it might work now for these 